\title{
Barmhartigheid in het publieke domein onder druk
}

\author{
Frans Jespers
}

\begin{abstract}
Eeuwenlang konden burgers vanzelfsprekend een beroep doen op de barmhartigheid van vorsten en rechters, speciaal bij juridische beslissingen. Maar tegenwoordig is dit soort barmhartigheid omstreden: een bestuurder of rechter die een uitspraak op barmhartigheid baseert, roept vaak kritiek op. De Amerikaanse politieke filosofen Alex Tuckness en John Parrish maakten een onderzoeksproject van deze vraag: waar komt de scepsis over barmhartigheid in het publieke domein vandaan? Zij zien nog steeds (beperkte) kansen voor deze deugd, ook binnen publieke functies. Ik heb twijfels bij de adequaatheid van hun analyse en daarom bij hun conclusie. Maar mijn invalshoek, die van de vergelijkende godsdienstwetenschap, is ook beperkt. Eerst geef ik de conclusies en de hoofdlijnen van de historische analyse van de studie van Tuckness en Parrish weer. Daarna presenteer ik enige kanttekeningen.
\end{abstract}

\section{Een weinig barmhartig publiek domein}

De Amerikaanse politiek filosofen Tuckness en Parrish vonden elkaar in de probleemstelling van de scepsis over de deugd van barmhartigheid in het publieke domein en maakten er een meerjarig onderzoeksproject van. Dit resulteerde in een systematische studie, The Decline of Mercy in Public Life. ${ }^{1}$ De titel verraadt hun conclusie: er is sprake van onterecht verval. De westerse cultuur is bezig om een belangrijke waarde, of althans een belangrijk aspect ervan, te verliezen.

Met enkele voorbeelden maken de auteurs in de inleiding duidelijk wat zij bedoelen met barmhartige daden in het publieke domein (p. 2-4). De minister die een groep illegale migranten amnestie verleent. De gouverneur van een staat die (soms collectief) gratie verleent aan terdoodveroordeelden. De ambtenaar bij sociale zaken die ruimhartig is met toekenning van uitkeringen. De oproep tot barmhartigheid in debatten over toelating van vluchtelingen, over kwijtschelding van woekerhypotheken of over lagere strafmaten in de rechtspraak. Het gaat de auteurs speciaal om de politieke of bestuurlijke toepassing van barmhartigheid. Zij vragen zich af of deze deugd nog wel als argument gebruikt wordt, of mag wor-

1 A. Tuckness \& J.M. Parrish, The Decline of Mercy in Public Life, Cambridge 2014, 300 pag., ISBN 9781107661134. Alex Tuckness is hoogleraar Politicologie en Politieke filosofie aan Iowa State University en John Parrish is hoofddocent Politicologie aan Loyola Marymount University. 
den, dan wel of bij al deze voorbeelden eigenlijk andere waarden voorop (moeten) staan, zoals rechtvaardigheid, waardigheid, rehabilitatie, billijkheid of gelijkheid. Over de deugd van individuele barmhartigheid of compassie bestaat in onze (westerse) samenleving nauwelijks twijfel. Verder laten de auteurs nog een ander type van barmhartige daden in het publieke domein buiten de discussie. Het betreft bijvoorbeeld humanitaire acties; denk aan geldinzamelingen na een natuurramp ergens in de wereld. Zulke publieke acties vinden geregeld plaats, maar de auteurs suggereren dat dit eigenlijk lovenswaardige particuliere initiatieven zijn. Ook beperktere activiteiten zoals zorg van burgers voor armen of gehandicapten, of het opkomen voor verdrukte groepen, ondervinden weinig tegenspraak.

Vandaar de probleemstelling van Tuckness en Parrish: hoe en waarom ontstond de scepsis over barmhartigheid (in voornoemde politieke zin)? Zij zoeken een antwoord met behulp van een vergelijkende en historische studie naar dit soort barmhartigheid. Ik vat eerst hun conclusies samen.

\section{De complexe deugd van publieke barmhartigheid}

Zo eenvoudig als barmhartigheid als particuliere deugd lijkt te zijn, zo complex is de publieke of politieke versie ervan. Individuele barmhartigheid is het uit mededogen belangeloos of om niet schenken van goederen of iets anders in ruimere mate dan redelijkerwijs verwacht mag worden. Maar een bestuurder in overheidsdienst heeft hiervoor nauwelijks speelruimte. Als er al ruimte is, wordt die gewoonlijk door andere waarden genormeerd dan barmhartigheid. Er is wel consensus over drie voorwaarden die in alle vormen van barmhartigheid een rol spelen: de ongelijke status van de betrokken partijen, de toekenning van een gift (of vermindering van een last), en de discretionaire competentie van de verlener (het vermogen om onderscheid te maken tussen wat verplicht en wat toegestaan is, en wat het gewicht van bijkomende omstandigheden is) (p. 252).

In discussies over de mogelijkheid van publieke barmhartigheid wordt de verwarring gevoed door een (vaak onuitgesproken) beroep op verschillende metaforen van barmhartigheid. Tuckness en Parrish onderscheiden vier basismetaforen (p. 11): de milde rechter, de schuldeiser die schuld kwijtscheldt, de weldoener en de liefdevolle ouder. Deze werden in klassieke redeneringen soms anders gebruikt dan tegenwoordig. Hedendaagse utilitaristen prefereren de schuldeisersmetafoor (p. 258). Verder worden discussies bemoeilijkt wanneer aspecten of dimensies van barmhartigheid worden verward, waarbij de auteurs er vijf onderscheiden: omstandigheden, redelijke of wettelijke verwachting, verplichting, motief en effect of gevolg (p. 11, 256). Zij stellen vast dat tegenwoordig voor alle vijf de dimensies verschillende standpunten tegenover elkaar staan, maar de belangrijkste tegenstelling betreft de tweede dimensie.

Bij deze dimensie lopen we volgens Tuckness en Parrish aan tegen de spanning tussen barmhartigheid en rechtvaardigheid (p. 261 e.v.). In moderne rechtsstaten geeft de wetgeving de grenzen, categorieën en gradaties aan waarmee bestuurders en rechters moeten werken. Barmhartigheid, waarin juist een grens overschreden of een regel opgeschort wordt, is dan een bedenkelijke houding. Die spanning tus- 
sen rechtvaardigheid en barmhartigheid is pas in de afgelopen eeuwen ontstaan, want tot en met de Middeleeuwen was er eerder sprake van inpassing van menselijke barmhartigheid (van de vorst, de rechter) in de door God gewilde retributieve rechtsorde. Dit is een rechtsorde waarin misdadigers worden gestraft op een wijze die de misdaad vereffent (of vergeldt), dus met een straf die overeenkomt met het gewicht van het vergrijp. Na de Reformatie zijn de opvattingen over staat, bestuur en burgers zodanig veranderd dat publieke barmhartigheid een riskante deugd is geworden.

Toch wagen Tuckness en Parrish zich aan een verdediging van barmhartigheid in publieke functies door tegemoet te komen aan de vier belangrijkste bezwaren ertegen. Het eerste bezwaar is willekeur: burgers, zowel misdadigers als slachtoffers, moeten gelijk en onpartijdig behandeld worden. De auteurs menen dat in ons complexe strafrecht zoveel afweging moet plaatsvinden op basis van discretionaire competentie, dat hierbij soms, onder voldoende voorwaarden (zoals verantwoording en mogelijkheid van beroep), van barmhartigheid gesproken kan worden (p. 274-281). Het tweede bezwaar is dat een rechter door barmhartigheid te betonen een bevoegdheid van het slachtoffer overneemt (overschrijding van de morele status), maar hier kan een rechter nadrukkelijk rekening mee houden door slachtoffers inspraak te geven (p. 281-283). Het derde bezwaar betreft een mogelijk nadeel voor het algemeen belang, dat is te ondervangen door hier speciaal op te letten (p. 284-286). Het vierde bezwaar houdt in dat barmhartigheid tot onjuist gebruik van discretionaire bevoegdheid leidt, namelijk overschrijding van wettelijke voorschriften. Maar hier brengen de auteurs tegen in dat dit een eenzijdig retributief argument is, dat te weinig rekening houdt met een zekere onachterhaalbaarheid van motieven van misdadigers (p. 287-289). Kortom, de auteurs menen dat onder strikte voorwaarden en met inachtneming van heldere begrippen in sommige situaties wel degelijk van barmhartigheid sprake kan zijn. Zij trekken deze conclusies op basis van een historisch overzicht van 'theologische en politieke aannames' (p. 6), waarvan ik nu de hoofdzaken weergeef.

\section{Barmhartigheid in enkele grote godsdiensten}

Tuckness en Parrish selecteerden drie uiteenlopende religieuze tradities om aan te tonen dat de opvattingen over barmhartigheid flink kunnen verschillen. De eerste religie is het boeddhisme, waar compassie een sleutelbegrip is: een goed mens probeert altijd bij te dragen aan vermindering van het lijden van andere wezens (p. 32). Barmhartigheid valt ongeveer samen met dit mededogen. Een vorst die het recht moet handhaven, staat altijd voor de moeilijke taak om misdadigers niet onnodig zwaar te straffen en tegelijk met het algemene welzijn rekening te houden. In sommige boeddhistische stromingen is een retributief rechtssysteem dan ook uitgesloten, omdat dit te veel gebruik van (straffend) geweld zou oproepen.

De tweede religieuze traditie die behandeld wordt is de islam. Allah is een strenge, rechtvaardige God, maar tegelijk is hij barmhartig in twee betekenissen: vergevend en ondersteunend. Gods barmhartigheid berust op zijn soevereine wil en 
alwetendheid (p. 40). Maar menselijke bestuursverantwoordelijkheid (van vorsten en rechters) is gebonden aan de door God gestelde wetten (p. 41). Een goede samenleving vereist toepassing van strenge straffen.

Tot slot staan de auteurs stil bij de oosters-orthodoxe kerken. In hun theologie is God vooral genadig, een weldoener (p. 46). Ook menselijke bestuurders moeten zorgzaam zijn, zelfs in strafzaken. Uit de visie op barmhartigheid in deze drie tradities concluderen de auteurs dat er nergens sprake is van een spanning tussen barmhartigheid en rechtvaardigheid, die juist kenmerkend lijkt voor de westerse situatie.

\section{De westerse filosofische en theologische geschiedenis}

In de Oudheid kreeg barmhartigheid geheel andere connotaties (p. 54-82). Een misdaad werd primair opgevat als een schending van de eer die om wraak en gepaste vergelding vroeg: oog om oog. Barmhartig is dan een vorst of leider die zijn gekwetste woede weet te beheersen. Plato drong echter aan op een redelijk strafsysteem dat gericht is op afschrikking en rehabilitatie, waarbij barmhartigheid zoveel betekent als mildheid (leniency). Aristoteles nuanceerde deze deugd meer in de richting van billijkheid (equity), goed afwegen van omstandigheden. Bij de Stoa stond onpartijdig strafrecht voorop, maar enige clementie getuigde volgens hen van de grootheid van een vorst.

Vervolgens speelde Augustinus een sleutelrol in de geschiedenis van de barmhartigheid. Volgens hem is Gods rechtvaardigheid vergeldend (retributief) van aard. Gods oordelen zijn liefdevol, maar voor mensen onbegrijpelijk. Gelovigen moeten elkaar ook liefhebben (caritas). Maar politieke bestuurders moeten naar Bijbelse regels misdadigers veroordelen om hen te brengen tot inkeer en verbetering, waaraan mildheid ook kan bijdragen (p. 101). Deze opvatting vestigde in het westerse christendom voor vele eeuwen een retributieve rechtsopvatting, die door bijvoorbeeld Anselmus nog versterkt werd (p. 113-114). Latere theologen zoals Thomas van Aquino en de reformatoren Luther en Calvijn handhaafden deze retributieve visie. Als gevolg hiervan stelden zij dat vorsten en rechters streng moesten straffen.

De auteurs besteden bij elk van deze theologen uitgebreid aandacht aan hun versie van de verzoeningsleer als een soort toppunt van goddelijk strafrecht: God stond toe dat Christus de kruisdood onderging om daarmee de zonden van alle mensen uit te boeten. Zij betogen dat de opvatting over het goddelijk strafrecht een logische tegenhanger krijgt in het menselijke strafrecht en de mogelijkheid van barmhartigheid in het publieke domein. Deze samenhang verschoof in de zestiende eeuw naar een spanning tussen rechtvaardigheid en barmhartigheid.

Hugo de Groot hield vast aan het reformatorische godsbeeld. Maar zijn visie op de toedeling van straf ging in de richting van het voorkomen van toekomstig kwaad en het veiligstellen van de natuurlijke sociale orde (natuurrecht). De rechter mag clement zijn, maar niet tegen de wet ingaan. Dit laatste mag alleen de wetgever op basis van afwijkende omstandigheden (p. 144-150). Bij Hobbes en Locke lag de nadruk in het strafrecht op straffen met het oog op de toekomst (van de misdadi- 
ger en de samenleving). Een nieuw, liberaal element was de eis van gelijke en onpartijdige behandeling. Hierdoor bleef de speelruimte voor een barmhartige opstelling van een vorst of rechter beperkt tot toepassing van mildheid, binnen de kaders van de wet (p. 155-156). Want zowel de vorst als de rechter is gebonden aan de soevereiniteit van het volk en daaraan verantwoording verschuldigd. Parallel hiermee veranderde in de zeventiende eeuw de opvatting over armenzorg van particuliere weldadigheid naar plicht en naar bijstand als een recht. Het verlenen van deze bijstand werd een taak van de staat.

In de achttiende eeuw zetten Hume en Beccaria de utilitaristische benadering voort. Dit leidde tot een distributieve rechtsopvatting, met een pleidooi voor een beperkte, zinvolle strafmaat die rationeel te verantwoorden is (p. 172-179). In combinatie met de eis van een betrouwbaar strafsysteem (Montesquieu) liet dit nog maar minimale ruimte over voor barmhartigheid. Een rechter kan op z'n hoogst mild zijn in de classificatie of toepassing van de in de wet vastgelegde strafmaten. Adam Smith deed hiervoor een beroep op een denkbeeldige 'onpartijdige toeschouwer', soms voorgesteld als God die over de schouder van de rechter meekijkt en diens gevoelens wat indamt (p. 190-192). Ook latere utilitaristen zoals Bentham en Mill legden voor het strafrecht de nadruk op toekomstgerichtheid, maar tevens op de betrouwbaarheid van het systeem. Het gevolg van dit standpunt is dat barmhartigheid dan leidt tot onzekerheid en daarom wreed wordt genoemd. Ook in onze tijd hanteren utilitaristen (Ronald Dworkin, Ross Harrison) de genoemde uitgangspunten, waardoor barmhartigheid vrijwel is uitgesloten (p. 217-218).

Kant had een pessimistischer mens- en wereldbeeld, waarbij een retributief strafrecht (ius talionis) hoort (p. 225-238). Een onpartijdig strafsysteem garandeert de vrijheid en gelijkheid van de burgers in een staat. Dit laat voor de rechter geen barmhartigheid toe, want hierbij dreigen gevoelens van medelijden een rol te gaan spelen die de onpartijdigheid in gevaar brengen. Hedendaagse retributivisten (Jeffrie Murphy, Herbert Morris) leggen meer nadruk op de eerlijkheid (fairness) van het systeem (p. 242-243).

Hiermee zijn de hoofdpunten uit het betoog en de historische analyse van Tuckness en Parrish samengevat. Ik kan niet verifiëren of hun weergave van de grote denkers correct is, maar zij beroepen zich op vooraanstaande commentatoren en blijven binnen gangbare opvattingen. Nu ga ik over naar mijn kritische kanttekeningen.

\section{Religieuze perspectieven}

Het lijdt geen twijfel dat in de meeste godsdiensten individuele barmhartigheid een grote deugd is. Gelovigen kunnen zich verdiensten verwerven door meer te schenken of te vergeven dan redelijkerwijs verwacht mag worden. Karen Armstrong heeft hier zelfs een soort interreligieuze methodiek voor ontwikkeld in haar boek Compassie. ${ }^{2}$ Zij wil hiermee aannemelijk maken dat de particuliere 
barmhartigheid die in zoveel religieuze tradities wordt nagestreefd ook in een geseculariseerde samenleving onmisbaar en verrijkend is.

Maar voor barmhartigheid in publieke functies liggen de kaarten anders. In gebieden waar traditionele godsdiensten overheersen, worden vorsten en rechters meestal beschouwd als van hogerhand gemandateerde overheden. Zij moeten de sacrale orde in stand houden door streng op te treden en terughoudend te zijn met barmhartigheid. Hierbij maakt het weinig uit of deze sacrale orde een kosmische instantie is waaraan zelfs de goden onderworpen zijn (de dharma in hindoeïsme en boeddhisme, de tao in het taoïsme en confucianisme, het noodlot bij Grieken en Romeinen), of berust op de wil van een persoonlijke godheid (in islam, jodendom en christendom). Maar in de praktijk kunnen veel bestuurders deze plicht naar hun hand zetten omdat zij ook de concrete interpretatie van de sacrale orde beheersen. In veel Afrikaanse en Aziatische landen maken bestuurders en rechters nog steeds geregeld gebruik van hun discretionaire macht om gratie te verlenen of straffen te verlichten, maar omgekeerd ook om zwaarder te straffen. ${ }^{3}$ De sacrale orde is vaak een legitimatie voor willekeurige machtsuitoefening. Tuckness en Parrish zijn zich hiervan bewust, zoals zij in een passage over de analyse van Michel Foucault erkennen (p. 15-18), maar zij kiezen voor een ideeënhistorische benadering.

Tuckness en Parrish hebben met hun interreligieuze vergelijking vooral de uitzonderlijke positie van het westerse christendom willen onderstrepen, waar een spanning tussen rechtvaardigheid en barmhartigheid is gegroeid die in andere godsdiensten niet voor lijkt te komen. Zij menen dat de verklaring voor deze ontwikkeling ligt in de veranderende opvatting over de goddelijke rechtsorde, die weer prominent zichtbaar is in de verschillende verzoeningstheologieën. Hoe strenger het godsbeeld was, des te minder speelruimte bleef er voor barmhartigheid van vorsten en rechters.

Ik meen dat hun historisch overzicht juist laat zien dat de omslag naar afschaffing van barmhartigheid in publieke functies vooral een gevolg is van de modernisering. Sinds de zestiende eeuw zijn filosofen het strafrecht gaan baseren op gelijkheid, onpartijdigheid, volkssoevereiniteit en zekerheid, waardoor uitoefening van rechtvaardigheid nauwelijks speling, laat staan grensoverschrijding (barmhartigheid) toelaat. Toch is het een verdienste dat Tuckness en Parrish de ideeën van door hen behandelde denkers interpreteren vanuit de context van hun tijd. Wanneer dit niet gebeurt, wordt de discussie over barmhartigheid in het publieke domein al snel ondoorzichtig.

Een recent voorbeeld van dit laatste is een pleidooi van Fred van Iersel voor een barmhartige opvang van vluchtelingen door de (Nederlandse) overheid, waarmee hij vooral doelt op een ruimhartige opstelling van politici en parlement. ${ }^{4}$ Hierbij beroept hij zich tamelijk onbekommerd op de politieke visies van Augustinus en Thomas van Aquino op de taak van de staat. Maar wanneer deze premoderne theologen vaststellen dat de staat primair de rechtvaardigheid in stand moet hou-

3 Vgl. M. Backman, The Asian Insider: Unconventional Wisdom for Asian Business, Houndmills/New York 2006.

4 F. van Iersel, 'Een barmhartige overheid', Christen Democratische Verkenningen 2016, 1, p. 57-63. 
den, verwijzen zij naar een goddelijke orde en niet naar de in wetten vastgelegde nationale rechtsorde die wij laatmodernen eronder verstaan. Verder sluit Van Iersels betoog goed op dat van Tuckness en Parrish aan, want hij stelt dat een barmhartige opstelling van de overheid wordt begrensd door rechtvaardigheid en veiligheid. Tegelijk beperkt Van Iersel de speelruimte van de barmhartige overheid tot de rol van politici in het publieke debat en in het parlement. Het type van barmhartigheid in publieke functies waarnaar Tuckness en Parrish zoeken, komt bij hem niet ter sprake.

\section{Seculiere perspectieven}

De tegenstelling met de moderne westerse opvatting wordt veroorzaakt door de moderniteit, die met een nieuw wereldbeeld ook een nieuwe opvatting over de samenleving tot stand bracht. ${ }^{5}$ Deze wereld kent haar eigen natuurwetten, aanvankelijk voorgesteld met en later zonder goddelijk toezicht. Op sociaal en politiek gebied zijn alle mensen gelijkwaardig en moeten zij in goed overleg (sociaal contract) hun eigen nationale wetgeving afspreken. Het volk van een natie is soeverein en kent bevoegdheden toe aan bestuurders en rechters. Deze personen hebben enige discretionaire bevoegdheid, waarbij de speelruimte beperkt blijft tot mildheid, billijkheid of clementie binnen de marges van de wet. Zij mogen geen barmhartigheid uitoefenen in de zin van overschrijding van regels of wetten. Maar barmhartigheid kan wel als argument gelden voor de wetgevende instantie, het parlement, dat wetten kan aanpassen of eenmalige regelingen kan treffen, zoals amnestie voor een bepaalde groep personen. Ik betwijfel of moderne christenen hier anders over denken dan seculier ingestelde westerlingen. Ook liberale moslims (zoals Bassam Tibi of Mohammed Arkoun), hindoes of boeddhisten zullen dezelfde mening zijn toegedaan. Het argument voor eventueel ruimhartig handelen zal dan ook meestal seculier of humanitair zijn: rechtvaardigheid, mildheid of zorgzaamheid.

Ik wil nog op een eigenaardige parallel wijzen, die van het confucianisme. In oorsprong is dit de oudste vorm van humanistische filosofie, zoals sinoloog Kristofer Schipper het denken van Confucius (551-479 v.Chr.) typeert. ${ }^{6}$ Rond het begin van onze jaartelling is het uitgegroeid tot een complete religie, met goden, tempels en rituelen. De confucianistische sociale ethiek vereist van bestuurders de hoogste deugdzaamheid, die voor alle burgers tot voorbeeld moet strekken. Bestuurders en rechters dienen het volk en passen de wetten nauwgezet maar billijk toe. De hoogste bestuurder, de koning, moet tegelijk de grootste wijze zijn die de juiste barmhartigheid of medemenselijkheid (ren) heeft gevonden als een balans van trouw aan de regels (zhong) en empathie met mensen $(s h u) .{ }^{7}$ Dit premoderne

5 Zie C. Taylor, A Secular Age, Cambridge/Londen: Belknap Press 2007 (Nederlandse vertaling: Een seculiere tijd, Rotterdam 2009).

6 Confucius, De gesprekken, vertaald en toegelicht door Kristofer Schipper, Amsterdam/Antwerpen: Augustus 2014, p. 13, 95.

7 J. Liu, An Introduction to Chinese Philosophy: From Ancient Philosophy to Chinese Buddhism, Oxford 2006, p. 48-62. 
humanisme vertoont al de spanning tussen rechtvaardigheid en barmhartigheid. Het confucianisme spoorde bestuurders in China eeuwenlang aan tot medemenselijkheid, maar kon in de praktijk ook willekeur en wreedheid niet voorkomen. Zelfs in de huidige Volksrepubliek probeert de overheid deze confucianistische deugden weer aan bestuurders op te leggen, in het kader van een communistische rechtsorde, maar de resultaten zijn niet bemoedigend vanwege de machtspolitiek van de partij. ${ }^{8}$ Alleen in kleinere staten zoals Taiwan en Singapore is de seculiere sociale ethiek van het confucianisme opgenomen in een democratische rechtsstaat, waar dan evenals in het Westen de spanning tussen rechtvaardigheid en barmhartigheid een rol speelt.

\section{Conclusie}

Tuckness en Parrish hebben een boeiend thema uit de sociale en politieke ethiek aan de orde gesteld door de mogelijkheden van barmhartigheid in publieke functies te onderzoeken. Zij hebben gelijk wanneer zij vaststellen dat discussies hierover te lijden hebben van het gebruik van onduidelijke begrippen en metaforen. Maar in argumentaties speelt zeker ook de religieuze connotatie van barmhartigheid als deugd mee. Dit religieuze aspect wordt in een seculiere samenleving als de onze door velen niet als aanbeveling opgevat. Om deze ambivalentie te vermijden geven auteurs zoals Armstrong dan ook de voorkeur aan het neutralere begrip compassie. Vervolgens zijn de argumenten voor barmhartigheid in het politieke debat en de wetgeving, door politici en parlement, nog overtuigend, wat we door Van Iersel bevestigd zagen. Maar de reeks voorwaarden waaraan barmhartigheid in bestuurlijke functies volgens Tuckness en Parrish moet voldoen, laat eigenlijk zien dat het hier vooral om mildheid, billijkheid en clementie binnen de grenzen van regels en wetten gaat en vrijwel niet om het overschrijden van grenzen. Misschien is hun pleidooi voor deze incidentele barmhartigheid vooral ingegeven door verontwaardiging over het (zeker in Europese ogen) rigide strafregime in de Verenigde Staten.

De vergelijking met opvattingen over barmhartigheid in niet-christelijke religieuze tradities is in het boek bescheiden gebleven. Maar een bredere vergelijking zou weinig nieuwe argumenten opleveren, omdat de grote overgang in het denken over barmhartigheid in het publieke domein gelegen is in die van een sacrale rechtsorde (in talloze varianten) naar een seculiere, egalitaire, in nationale staten en internationale verbanden vastgelegde rechtsorde. De hypothese van Tuckness en Parrish dat deze overgang tot een eenzijdige spanning tussen rechtvaardigheid en barmhartigheid heeft geleid, die gerelateerd is aan verschillende theologieën over de verzoening van God en mensen in de kruisdood van Christus, is in dit licht weinig aannemelijk. Zelfs hun centrale stelling is twijfelachtig: is de overgang van religieus geïnspireerde barmhartigheid van vorsten en rechters naar seculiere deugden zoals mildheid, billijkheid en clementie in bestuur en rechtspraak wel als verval van sociale ethiek aan te merken? Daar staat tegenover dat 
het gelovige burgers en denkers moet verontrusten wanneer het publieke en politieke debat, bijvoorbeeld over vluchtelingen, minder barmhartig wordt. Maar dit debat moet gevoed worden door ervaringen, overtuigingen en argumenten van onderaf. Hierbij lijkt het beroep op een neutraler klinkende deugd zoals compassie betere kansen te bieden. 